\title{
Loneliness of human in the philosophy of Ernst Bloch culture
}

\author{
Pavel Lyashenko ${ }^{1 *}$, and Maxim Lyashchenko ${ }^{1}$ \\ ${ }^{1}$ Orenburg State University, 460018, Orenburg, Russia
}

\begin{abstract}
The problem of loneliness from the view point of philosophical and anthropological knowledge acquires special significance, is filled with new content in connection with the unfolding of the modern society transformation processes, as a result, with a new stage in the reappraisal of the modern culture utopian consciousness. At the same time, Ernst Bloch's culture philosophy induce particular scientific interest, according to which the meaningful status of utopia is determined by the fact that it forms a certain ideal image of the human world, which is the space of culture as a whole. In this regard, the study of the loneliness phenomenon in Ernst Bloch culture philosophy allows us to identify the socio-cultural mechanisms of loneliness, as well as key factors in the development of modern society, leading the person to negation and the destruction of his being.
\end{abstract}

\section{Introduction}

Like a lot of factors that form the everyday world of human, loneliness, culture, utopia belong to the phenomena of human being that are complex for scientific and philosophical comprehension. Turning to the theoretical heritage of the past and modern philosophical research leads to mutually exclusive judgments about loneliness, about culture, and about utopia. Sometimes we come to the idea of the incompatibility of these phenomena, in the absence of any strong and stable connection between them. And even the immense wealth of theoretical approaches and the variety of empirical studies do not allow a holistic and unified image of these phenomena connection in our minds. In addition, many separate, very important, but little studied aspects of the loneliness problem in conjunction with the problem of utopia as the pinnacle of philosophical thinking and the "core" of spiritual culture that provides for transcending and, at the same time, the construction of human and world ideal models constantly slip away. This problem has a practical orientation: the problem of utopia is the problem of the presence or absence of a meaningful future (an ideal goal), which is the main factor that inspires society and individuals to realize and practically improve themselves. In the light of this problem formulation, a number of questions arise: Is there any future for a lonely person? Can a person, society and culture exist without clearly meaningful goals? Russian society is on the verge of this. Therefore,

* Corresponding author: lyashenkopavel@rambler.ru 
the life and destiny of society depends on how quickly it can discover the desired future. So the life and fate of lonely people depends on the same.

\section{Statement of a fundamental scientific problem}

Reconstruction of E. Bloch's philosophical representation of loneliness from the point of view of utopian consciousness in culture is the heart of the research.

An analysis of the research current state of the scientific problem of human loneliness in the Ernst Bloch's culture philosophy has demonstrated that, firstly, loneliness as a complex philosophical-anthropological and philosophical-cultural category has not been systematically studied in the context of modern socio-cultural processes of a transforming society; secondly, the phenomenon of loneliness is not sufficiently disclosed in connection with the utopian consciousness in the E. Bloch culture philosophy.

\section{Research Methods}

The research, setting its main task to rethink the category of loneliness in the E. Bloch's culture philosophy highlights the philosophical and anthropological aspect; involves putting forward ideas that help predict the future of humanity. The fundamental methodological basis is the axiological approach of a philosophical rational worldview, which allows combining such aspects of E. Bloch's philosophical and axiological anthropology as:

- the phenomenon of human loneliness,

- human being and culture,

- the existential value of utopian projects in anthropological reality.

The conceptual and semantic shift in the understanding of utopia, which in many respects anticipated its cultural and anthropological interpretation in the future, is found in the philosophical doctrine of Ernst Bloch, whose views, as a rule, relate to one of the existential anthropology directions. Offering his understanding of utopia, E. Bloch proceeds from an analysis of the existential model of human being and the subjective world, while pointing out the fundamental difference between his philosophical and anthropological views and Marxist philosophical theory. The thinker notes that K. Marx analyzes the social side of human being, while the "philosophy of hope" illuminates his ontic, personal world.

Refusing the critical line of the utopia study laid down by Marxist philosophy, E. Bloch reveals the anthropological and existential nature of this phenomenon, which makes it possible to overcome its one-sided interpretation as a social ideal, as something only external. According to E. Bloch, K. Marx "expelled all dreams, all acting utopias, all religiously roaming telos from history and ascribes to the production process the same essence, the same pantheism and mysticism, the same leading force that Hegel ascribes to the idea, and Schopenhauer for his illogical will" (Bloch E., 1985). That is, the philosophy of K. Marx, ascribing to the production process some absolute truths in the form of pantheism and mysticism, turns a person into something derivative and dependent on society, on its material basis. Therefore, "it is impossible to live in society and to be free from society" (Lenin V.I., 1955). This is on the one hand. But on the other hand, a person, speaking as a reflection of social relations, must nevertheless be recognized as a composed, creative being, "changing objective conditions and circumstances" (B. Grigoryan, 1973). It is in creativity that man manifests himself as a free being. Freedom - "this is the element of creativity", rebelling" against world givenness and necessity" (Dydrov A.A., Neveleva V.S., 2019). In fairness, it should be noted the primacy of the social whole, in the philosophical anthropology of K. Marx, over an individual. 
At the same time, according to E. Bloch, the goal of utopia is to revive the role of human in the world process, as well as the subsequent naturalization of human and the humanization of nature. For E. Bloch, the issue of utopia is a question mainly about a person, about the content and horizons of his activity in history and culture, as well as the transformation process of spiritual culture and the material world. On this basis, E. Bloch proclaims: "To be a Human means in reality to have Utopia" (E. Bloch, 1997). In the same context, the philosopher considered the title of the work by F. Engels "The Development of Socialism from Utopia to Science" unsuccessful, noting that the question should be posed in exactly the opposite way: "the concrete utopian is an objective-real degree (historical L.P.) reality on the front line of the emerging world - in the form of a still-non-existent "naturalization of human", "humanization of nature" (E. Bloch, 1991). In Utopia, according to E. Bloch, the latency of "success or failure of human history" and culture is hidden (Horacio Cerutti-Gulberg, 2016). Utopia in this context appears not so much as an ideal model of human existence, but as a "method of studying the history and culture of mankind" (Fernando Ainsa, 2016).

The starting point of the E. Bloch philosophy is the conceptual and methodological installation - "I am. But I don't have myself. And only therefore we become" (E. Bloch, 1997). This postulate, reflecting and developing the Kantian understanding of human as a creature that defines himself, leads E. Bloch to the idea of an essential desire to search and realize himself as the meaning-forming core of human existence. Under the influence of existential philosophy, E. Bloch, in essence, states that the internal conflict of the individual "I", his self-non-identity is the starting point for the search for his self and the process of constant self-constitution. This allows E. Bloch to define a person as a "restless Emptiness", "not achieved by Being-at-oneself". And the essential attributes of human life for the thinker are such characteristics as "Incognito", "Riddle", "Hidden", "Unspoken". It is worth noting that in the framework of this provision, E. Bloch continues the existential line of J.-P. Sartre philosophy, for whom "existence precedes essence," and human "first exists, meets, appears in the world and only then is determined" (Sartre J.-P., 1990). According to E. Bloch, the open, inexhaustible nature of human becomes an expression of the process of identification, self-determination of human as the basis for stability of the "picture of the world and the perception of oneself in time" (Erickson E., 1996).

Self-acquisition (identification) and self-construction of a person occurs alone (as, for example, in M. Heidegger or J.-P. Sartre) or in joint being? "From the pure Inside," as E. Bloch claims, "not a single verbal image arises that expresses the innermost silence of Inself and allows us to speak about it. ... So everything Inside becomes at first noticeable with the help of Outward; of course, not in order to thereby bring oneself to life, but to express oneself" (Bloch E, 1997). Loneliness is not the mode of being for E. Bloch, so that a person can identify himself. Only co-existence allows a person to identify and become internally complete and holistic.

The self-identity of the person expresses the deep nature of the human life world. The life world is considered by E. Bloch "from the point of view of the individual utopian intentions" (Vershinin S.E., 2001), in the form of a constant aspiration of his consciousness to the future as a point of "self-acquisition", expressed in the existential experiences of hope, dream, fantasy. If A. Schopenhauer unravels the great mystery of human being - the eternal present (Schopenhauer A., 1993), then E. Bloch, on the contrary, determines the human being and reveals it in the future, "Novum". In the utopian intention of consciousness, "the will to utopia" (Bloch E, 1991), according to E. Bloch, the paradoxical nature of the human being is manifested: human is the only creature overwhelmed by hope, the expectation of a better inspired life. Along with this, E. Bloch reinterpreting the thesis of F. Nietzsche on the "will to power", in essence, states that the will to utopia is a principle not only of human being, but of all mankind. The co-existential nature of utopia is the 
guarantor of the future discovery for the "I". There are no Others, there is no "I", just as there is no consciousness and there is no self-awareness. Consequently, utopia acts as a being way of a person in the world, his essential characteristic, which allows him to define "not only homo faber and homo ludens, but also homo utopicus" (Chalikova V., 1992).

The Thinker "insists that what a person can and could be is hidden in his "Inner, which requires initially expressing oneself "Outside". A person is "Incognito" for himself and for others, he has not yet developed, revealed himself and therefore "he is in conflict with all his existing definitions that want to be final" (Vershinin S.E., 1991). E. Bloch's way of avoiding the existential insecurity and dichotomy of the individual "I" is not a closure in an underdeveloped and deformed inner world, but an exit from oneself into the space of culture and society. Similar representation, E. Bloch is related to G.V.F. Hegel for whom "Nothing human is ever at rest" (Hegel G.V.F., 1978). Constant tension, the conflict of existence is the result of the development-disclosure of the "Inner". This process inevitably leads to self-negation, deconstruction, "Non-Estate" in the present, which serves as an incentive to self-determination, self-identification of a person in the future. Self-reflection in which a person predicts reflecting on himself "is the only way to find a new truth", since "the question of ourselves is the only problem resulting from all world problems; finding this Self- and We-problem in everything, opening paths for returning to one's homeland, crossing the whole world, is ultimately the main problem of utopian philosophy" (E. Bloch, 1997). Thus, the main problem of utopian philosophy, according to E. Bloch, can be revealed by the words of F.M. Dostoevsky: "Human is a secret. It must be revealed."

For E. Bloch, human exists, but does not possess himself. The "Inner", that is, the individual "I" acquires itself only through the appeal of "Outside" to the "You" and the world of culture. According to this thought, it can be noted that E. Bloch, in fact, confirms that along with biological and genetic codes, a person has another coding system, this is a culture understood as a socio-code through which programs of social behavior and activity are transmitted "(Bakhtiyarova E.Z., Chernikova I.V., 2019). From this theoretical position, E. Bloch opposes the existential methodology laid down by the philosophical theory of S. Kierkegaard, according to which everything, external, whether people, collisions with them, certain situations, is only a tool that allows you to contemplate, to reveal oneself: "external it becomes only a means, the goal is always the "I" (Gaidenko P.P., 1997). According to E. Bloch, the world of human and his existential space is determined through dialogue with "You," overcoming the alienation of the sensual, external world. It is no exaggeration to clarify that E. Bloch, defending the anthropological principle of L. Feuerbach, not only opposes the philosophy of G.V.F. Hegel, but also against the cultivation of singles in the philosophy of S. Kierkegaard and M. Heidegger. In his case, on the contrary, the social is not emasculated, but is the basis for constructing the "I". Otherwise, "it will remain Lonely, without any With-us, which is called not a faceless Someone, but We, and without any Around-us, which has constantly become and is becoming land for plants grown by human, material for houses built by him . Only then Around-us is pondered from within, thereby even closer to us. And just so it becomes less alien to human" (E. Bloch, 1997). For E. Bloch, the key element of the subjective reality of a person is the process of selfknowledge, self-identification, which finds its realization through the outlook, which appears in the form of a utopian-dialectic. A person does not represent his identity ("a construction not fixed once and for all, but rather a "assemblage point"... current fixation and identification of oneself in a changing chronotope (Emelin V.A., Rasskazova E.I., Tkhostov, 2018)") outside the world and society as constants of its being. That is, the fact that E.V. Ilyenkov called "the entrance to the realm of human culture."

E. Bloch was aware of the idea that "the subject, I, is not the center of subjective reality disconnected from the world, but a bodily embodied being (embodied self) in active interaction with the world and in communication with people" (V. Lektersky, 2017). My 
own "I", according to E. Bloch, is hidden in interaction with the "You", therefore, it is not only self-made, but also socially constructed. Thanks to the interaction with "You", it becomes possible to feel the integrity of individual human being. It is "You" that forms my "I", through the achievement of the unity of "We". In a dialogue with "You", selfknowledge of "I" takes place. Consequently, the subject of knowledge and self-knowledge, according to $\mathrm{E}$. Bloch, exists "only in the unity of the I, interhuman (intersubjective) relationships, cognitive and real activity" (V. Lektersky, 20001). Through the appropriation of an alienated world, the community development with others, the process of spiritual and moral development of a person and self-identification is realized. The space of culture and society determines and forms the existential space of the individual. Consequently, a person must be in an eternal search for possible forms of harmonization with the outside world and society, as the realization of a utopian integrity, meaning "precisely that freedom, that homeland of identity, where neither a person to the world, nor the world treats a person as an alien" (Bloch E., 1991).

The E. Bloch principle of anthropocentrism becomes an existential understanding of human as an imperfect and incomplete creature, driven by impulse, longing, hunger, "equally inherent in both body and spirit" (Vershinin S.E., 1997). The category "Not", being synonymous with hunger, the most important instinct and foundation of all human motives, acts as a form of "utopian-dialectical, advancing and advanced denial, such "Not" denies all peace, static and completeness" (Vershinin S.E., 1991). It is "Not" that constitutes the internal, driving force of human being and culture, acting as a means of decomposition of all inertness. The category "Not" acquires exclusively positive meaning from E. Bloch. "Not" acts as the starting point for any development and improvement of the human world and human in the world. "Not", "hunger" takes on E. Bloch a special ontological and epistemological status, allowing you to constantly overcome the horizon of human existence.

The hunger is mediated by E. Bloch with affects, instincts, motives. Affects, according to E. Bloch, can be divided into two large groups. So, "the first is the so-called filled emotions (envy, greed, veneration), the objects of which already exist as ready-made ones. The second is the affects of expectation (fear, anxiety, hope, faith), their subject is not yet ready, it does not even exist .... Hope is not only affect, but also the directing act of cognition. Hope is the most human of all movements of the soul; moreover, it is accessible only to human. It is associated with the farthest and brightest horizon" (Vershinin S.E., 2001). According to E. Bloch, hope nourishes the exaltation of the human spirit, gaining its value in culture. E. Bloch emphasizes the duality, ambivalent nature of hope, as an internal experience, feeling and hidden prerequisite for the development of human, society and culture. The category "hope" is attached to the "positive cosmic scale," that is, hope permeates not only human, but all matter as a whole. At the same time, hunger that arouses hope is a hunger of one's own worth in which a person manifests his inner "I". Hope is the motivation for what we do not have. This is a constant transition to a better future with the Other; this is overcoming the cold "IT" (M. Buber) and entering the space of the Meeting ("day dream" if we use the terminology of E. Bloch) - a living value-semantic space; lively communication with others, nature and the world.

The philosophical and anthropological meaning of the hope category is revealed in its connection with utopia. Hope is an attempt to go beyond the boundaries of being, the conductor of which is the process of revealing utopia. Utopia is expressed not only in a person's inner world, that is, in the direction of his consciousness inside and out for selfidentification, but also manifested in his activity: in work, in material and spiritual culture. In addition, utopia is the horizon of development of all material, in general, matter in its development and creation. Consequently, E. Bloch emphasizes the anthropologicalontological, universal nature of utopia. 
Turning to the affective side of human existence, E. Bloch points to the emotional, sensual nature of utopia, as one of the modes of human existence, which was repressed by a rational philosophical tradition, starting with Plato. And in the XVII century, in the era of the utopia emergence, "Pascal, admiring the greatness of human, notes that he was able to bring out a delightful device from lust - he refers to the social organization that Pascal describes as" such a wonderful order "(Gurevich P. S., 2018).

Overestimating the idea of $\mathrm{Z}$. Freud that "unfulfilled desires are the driving forces of fantasy," E. Bloch analyzes the category of hope in the context of the psychic unconscious, noting that hope is a source of daytime dreams. Based on the provision on the fragmentation of the individual "I", the separation of the subject from himself, the thinker argues that the integrity of consciousness is hidden in the "Still-Unconscious", human's day dreams of a better life (utopias). Since, "thinking of the best is initially an exclusively purely internal process of "I" (E. Bloch, 1991).

In the daytime dream, fantasy, in contrast to night dreams, the Self is constantly preserved, "such a Self that privately and consciously paints itself the states and pictures of the desired, a better life, portraying itself as the future Self" (E. Bloch, 1997). Daytime dream is the main meaningful and semantic core of utopia, reflected in mytho-poetic, fabulous and other images of the spiritual culture of mankind. Along with this "utopia is experienced in diverse anti-death paintings and the mysteries of desires in religions, the mysteries of hope in Christianity, which are closely interconnected" (E. Bloch, 1997). Spiritual culture itself, in its utopian dimension, acts as an activity to acquire a person of his essence, his "meeting with himself". In other words, in utopia, as a reflection of a daytime dream, a person again and again "poses ultimate questions to being and to himself" (Mironov V.V., 2019).

The day dream is acts as the unity of you and I, the co-existential basis of social reality. So, "if the sleeping person is lonely in his dreams and focused on oneself, then the dreamer's self is connected with other selves .... The day's dream is wider than the night one because it is connected with dreams of improving the world, it's more open, since it can and should be communicated to the other (others)" (Vershinin S.E., 1997).

\section{Conclusion}

A study of E. Bloch's culture philosophy on the issue of human loneliness, demonstrates a negative assessment of loneliness by a German thinker, for whom only being allows a person to identify, to become internally complete and holistic, which serves as the basis for constructing material and spiritual culture as a manifestation of the utopian sphere.

Recommendations and prospects for the further development of this research:

1) Although studies of loneliness and utopian consciousness are just beginning to emerge, they contain valuable heuristic potential for continuing further research not only on a theoretical but also on an empirical plane. For example, about the role of loneliness in the development of utopia, or a meaningful and reasoned ideal can lead a person out of a state of lonely "numbness" and inspire practical improvement not only of his spiritual and social "body", but also of perfecting life forms in general.

2) Future research should establish whether loneliness is the state in which new paths are opened for transcending a person and setting new horizons in his self-realization.

3) In the future, it will also be interesting to direct the vector of knowledge to the contradiction problem of the "dying" consciousness for a lonely person and the reviving utopian consciousness.

4) In subsequent studies, it is nevertheless promising to answer the question and the nature of the connection between loneliness and utopian consciousness in culture. 


\section{References}

1. E. Bloch, Tübingen Introduction to Philosophy (Publishing house of the Ural University, Yekaterinburg, 1997).

2. E. Bloch, The principle of hope. Utopia and Utopian thinking (Progress, Moscow, 1991).

3. E.Z. Bakhtiyarova, I.V. Chernikova, The problem of conceptualizing human development strategies, Vestnik of Tomsk State University. Philosophy. Sociology. Political science, 47, 5-15 (2019).

4. S.E. Vershinin, Introductory article. Bloch E. Tübingen Introduction to Philosophy (Publishing House of the Ural University, Yekaterinburg, 1991).

5. S.E. Vershinin, Ernst Bloch's Philosophy of Hope: Justification of Utopia (Yekaterinburg, 2001).

6. P.P. Gaidenko, Breakthrough to the Transcendent: A New Ontology of the XXth Century (Republic, Moscow, 1997).

7. Hegel, G.V.F., Political works (Nauka, Moscow, 1978).

8. B. Grigoryan, Philosophy about the essence of man (Politizdat, Moscow, 1973).

9. P.S. Gurevich, Nietzsche about human passions, Questions of philosophy, 8, 42-51 (2018)

10. A.A. Dydrov, V.S. Neveleva, Anthropology of innovations, Bulletin of Tomsk State University. Philosophy. Sociology. Political science, 48, 35-48 (2019)

11. V.A. Emelin, E.I. Rasskazova, A.Sh. Tkhostov, Unity and diversity of processes of formation of personality identity, Questions of philosophy, 1, 26-37 (2018).

12. V.A. Lector, Are representations of the subjective world an illusion? The subjective world in the context of the challenges of modern cognitive sciences (Aquilon, Moscow, 2017).

13. V.A. Lector, Subject. New philosophical encyclopedia. 3 (Thought, Moscow, 2001).

14. V.I. Lenin, Party organization and party literature. Full composition of writings (Politizdat, Moscow, 1955).

15. V.V. Mironov, Plato and the modern big-data cave, Bulletin of St. Petersburg University, Philosophy and conflictology, 35, 4-24 (2019),

16. J.P. Sartre, Existentialism is humanism. Twilight of the Gods (Politizdat, Moscow, 1990).

17. V. Chalikova, Utopia is born from utopia (Overseas Publications Interchange, London, 1992).

18. A. Schopenhauer, The world as a will and a representation (Nauka, Moscow, 1993).

19. E. Erickson, Identity: Youth and Crisis (Progress, Moscow, 1996).

20. E. Bloch, Geist der Utopie. ZweiteFassung. (Fr. M.,1985).

21. Horacio Cerutti-Gulberg, Fernando Ainsa: Soñador irredento, siempre adelante, Utopia y Praxis Latinoamericana, 21, 163-177 (2016).

22. Fernando Ainsa, Los senderos de la Utopía también se bifurcan. 45 años de viaje buscando llegar a alguna parte, Utopia y Praxis Latinoamericana, 21, 139-154 (2016). 